\title{
FRATERNIDADE NAS RELAÇÕES FAMILIARES: A IMPORTÂNCIA DO RESGATE PÓS PANDEMIA
}

\begin{abstract}
“A utopia está lá no horizonte. Me aproximo dois passos, ela se afasta dois passos. Caminho dez passos e o horizonte corre dez passos. Por mais que eu caminhe, jamais alcançarei. Para que serve a utopia? Serve para isso: para que eu não deixe de caminhar".
\end{abstract}

Eduardo Galeano

Dóris Ghilardi ${ }^{1}$ Ariani Folharini Bortolatto ${ }^{2}$ DOI: https://doi.org/10.47306/978-65-88213-03-2.357-367

Sumário: 1 Introdução; 2 Reflexões sobre Fraternidade; 3 O Princípio da Fraternidade e da Solidariedade no Direito de Família; 4 A Pandemia e as Relações Familiares: a Fraternidade como novo horizonte; 5 Considerações Finais; Referências.

\section{Introdução}

A inesperada pandemia causada pela difusão mundial do Coronavírus-19, responsável pela necessidade de confinamento social e as inúmeras dificuldades surgidas, seja de ordem sanitária, econômica, relacional ou psicológica, trouxeram consigo e ao debate importantes valores adormecidos como a empatia, a alteridade e a fraternidade.

Colocar-se no lugar do outro, deixar de lado o egoísmo, o individualismo para se pensar no coletivo, no todo, foram pautas recorrentes desde o início do isolamento. Diversas vulnerabilidades foram colocadas em evidência, exigindo maior atenção.

Um novo mundo se instalou e ressignificou importantes questões como o próprio tempo, redimensionado pela inovadora forma de trabalhar e de conviver. O contato físico cedeu lugar ao contato virtual, as tecnologias funcionaram como facilitadoras dos processos laborais, de

\footnotetext{
1 Professora Doutora, da Universidade Federal de Santa Catarina, lotada no Centro de Ciências Jurídicas. Coordenadora do Grupo de Pesquisa em Direito de Família em Perspectiva - GFAM/UFSC/CNPQ. Coordenadora Científica do IBDFAM-SC. E-mail: dorisghilardi@gmail.com

${ }^{2}$ Mestranda em Direito pela Universidade Federal de Santa Catarina. Especialista em Direito Processual Civil. Professora do curso de Direito da Faculdade CESUSC - Florianópolis/SC. Membro associada do IBDFAM/SC. Membro do Grupo de Pesquisa GFAM - UFSC/CNPQ. Pesquisadora e advogada. E-mail: arianifb@gmail.com.
} 
ensino e de vivência. Tudo isso também trouxe o aumento das angústias, das ansiedades e da violência doméstica. Direitos importantes passaram a ser violados.

Nesse cenário de anormalidade, repensar o modo de vida em família e em sociedade, desvela-se fundamental e concede abertura para a reinserção da fraternidade como pauta prioritária a ser não só debatida, mas também exercida por todos.

O objetivo central desse breve ensaio é resgatar o princípio da fraternidade no âmbito do Direito de Família, mormente no contexto que se instalou com a pandemia. Para tanto, esboça-se a ideia de fraternidade, realçando o fato de que deixou de ser tratada como mero valor ético, para ser transformada em norma jurídica. Após, busca-se identificar a fraternidade como princípio aplicável ao Direito de Família, evidenciando-se a sua substituição pelo princípio da solidariedade. Finaliza-se, então, com a tentativa de demonstrar a necessidade de avanço da dimensão da fraternidade/solidariedade sobre o plano fático, isto é, no dia-a-dia das relações familiares.

\section{Reflexões sobre fraternidade}

A etimologia da palavra fraternidade advém de frater que, em latim, significa irmão. Já a sua derivação fraternitas ou fraternitatis pode ter vários significados como: 1. Parentesco entre irmãos; irmandade; 2. Solidariedade entre irmãos; 3 . União ou convivência como de irmãos; 4. Amor ao próximo; fraternização; 5. Harmonia entre as pessoas da mesma comunidade e que lutam por um mesmo ideal; fraternização. (DICIONÁRIO MICHAELIS)

A ideia da fraternidade permeia o discurso histórico desde os tempos antigos, ganhando maior realce no início da Idade Moderna, sendo resgatada na contemporaneidade após um período de abandono.

A sua compreensão e alcance mudaram ao longo do tempo. No Direito Romano, a fraternidade estava vinculada aos laços de sangue, à ideia de irmandade. No Cristianismo difundiu-se a ideia de que todos são filhos de Deus, enquanto na Idade Moderna ocorreu a abstração de seu sentido religioso para passar adquirir uma dimensão política.

Ao lado da liberdade e da igualdade, a fraternidade passou a completar o tripé de valores da Revolução Francesa, constando no art. 1 da Declaração dos Direitos do Homem e do Cidadão que "Todos os seres humanos nascem livres e iguais em dignidade e direitos. São dotados de razão e consciência e devem agir em relação uns aos outros com espírito de fraternidade”. 
Contudo, a história que se seguiu não conseguiu manter unidos os três pilares, enquanto a liberdade e a igualdade foram alçadas pelo pensamento moderno como autênticas categorias políticas, concebidas como princípios constitucionais ou ideias-força de movimentos políticos, a fraternidade, alicerce das outras duas, ficou esquecida, como bem pondera Baggio (2008, p. 53) "seja por fraqueza, por medo das implicações, seja pela eclosão do conflito entre religião e modernidade, que tornou particularmente cheio de obstáculos o terreno da fraternidade".

A fraternidade, conforme especulam vários autores, seria o valor mais difícil de ser concretizado, seja por estar vinculado a uma conotação religiosa ou assistencial (PEZZIMENTI, 2008), seja por sua vinculação com uma 'ética da solidariedade', que é sempre ética e não política, ou seja, é um valor mais difícil de se realizar enquanto categoria política (TOSI, 2009).

Além disso, após a Revolução Francesa, a palavra fraternidade foi sendo gradativamente substituída pela expressão solidariedade, "a partir da idéia de que um laço fraternal une todos os homens numa só família, a partir de uma base religiosa (...)”. (ANDRADE, 2010, p. 28).

Entretanto, a fraternidade é mais ampla do que a solidariedade ou, conforme explica Baggio (2008), a solidariedade aplica parcialmente os conteúdos da fraternidade, permitindo, por exemplo, "que se faça o bem aos outros embora mantendo uma posição de força, uma relação 'vertical' que vai do forte ao fraco (...)".

Praticamente na mesma linha, Pizzolato (2008, p. 113) salienta de que a "fraternidade é uma forma de solidariedade que se realiza entre iguais", ou, em outras palavras, a solidariedade admite a desigualdade, enquanto a fraternidade trata das relações horizontais, sem espaço para a hierarquia, eis que os elementos se colocam no mesmo plano.

Representa a fraternidade, portanto, não só uma expressão ou uma ideia que vai além da solidariedade e do sentimento subjetivo, ela promove o compartilhamento da condição humana, da dignidade humana como postulado normativo, a própria consciência desse "lugarcomum". (PREIS; LYRA, 2018, p. 37).

Logo, é possível compreender a fraternidade como um verdadeiro paradigma que alicerça a democracia e que está no cerne da defesa dos direitos humanos, em que pese não se limitar as estruturas, tipo de organização social ou "comunidade politicamente institucionalizada". (LOPES, 2011, p. 102).

Contemplada como categoria jurídica em diversos ordenamentos, no Brasil a fraternidade foi estabelecida como princípio orientador e como forma de realização da vida e da harmonização social do Estado Democrático de Direito (BASTIANI; PELLENZ; AQUINO, 2015, p. 968). Consta do preâmbulo da Constituição da República Federativa do Brasil de 1988, 
que a instituição da democracia destina-se a "assegurar o exercício dos direitos sociais e individuais, a liberdade, a segurança, o bem-estar, o desenvolvimento, a igualdade, e a justiça como valores supremos de uma sociedade fraterna, pluralista e sem preconceitos, fundada na harmonia social (...)."

Apesar da adoção, no texto constitucional, da fraternidade como um dos valores supremos da sociedade democrática, não há nenhuma previsão de mecanismos jurídicos para que este cenário ocorra, o que não pode ser usado como um empecilho para a concretização de uma sociedade mais fraterna, já que esta realização não deve partir apenas do Estado, mas sim dos próprios seres humanos, que precisam internalizar como desejo e promover por meio de atitudes e ações uma maior sensibilidade social, equilibrando interesses e deveres, e, ainda, resgatando valores que requerem alteridade, empatia, respeito e comunhão, esquecidos a maior parte do tempo.

A fraternidade está no âmago das atitudes que exigem responsabilidade social e comprometimento com o próximo e requer importantes transformações em prol do bem comum e de relações mais recíprocas e harmoniosas.

No mundo atual, globalizado, multifacetado e que prioriza e incentiva o individualismo, as pessoas pouco escutam, na maior parte das vezes, exigem os seus direitos, sem se importar com o ponto de vista alheio, praticamente não havendo espaço para o diálogo ou o direito do outro. Por isso, a dimensão do coletivo e do outro precisa ser resgatada. O equilíbrio entre direitos e deveres precisa ser restabelecida.

Nesse cenário, é preciso que se diga que o direito não é responsável pela construção de uma sociedade mais fraterna, embora possa servir como importante mecanismo de facilitação para ações mais fraternais, na medida em que tem como função promover a capacidade de escutar o outro, de promover a igualdade e de respeitar as diferenças.

Não é o que normalmente se vê. É bem por isso que o mais importante nessa pauta, é fazer com que as pessoas se apropriem de seus conflitos e os resolvam sozinhos. A fraternidade é capaz de recolocar em "questão a comunhão de pactos entre sujeitos concretos com suas histórias e suas diferenças. Ciente de que a vida excede o direito, um bom modelo de convivência jurídica deve evitar colonizar a intimidade. ” (PREIS; COSTA LYRA, 2018, p. 31)

Nessa linha de pensamento é que o direito fraterno surge como importante "processo de auto-responsabilização, um caminho para a consciência de direito e deveres entre os seres humanos, exigíveis direta e horizontalmente (...)”. (GIMENEZ, 2018).

A pandemia causada pela rápida disseminação do vírus da COVID-19, responsável por fazer exsurgir dificuldades e restrições impensáveis, foi capaz de escancarar as fragilidades 
sociais e econômicas de um mundo individualista, consumista e de ritmo desenfreado. As restrições sanitárias e de isolamento impostas mundialmente paralisaram atividades, frearam a velocidade dos acontecimentos, modificaram posturas e fizeram sentir que a engrenagem é feita de muitas peças que exigem cooperação. A responsabilização pelo outro foi posta em evidência e, embora nem todos tenham compreendido, a fraternidade encontrou terreno fértil para ser desenvolvida.

Em meio às incertezas, os governos foram chamados a agir na tentativa de minimizar a crise, salvando vidas, protegendo empregos e diversos setores produtivos. Empresas e indivíduos passaram a se engajar com as necessidades alheias, promovendo ações solidárias que a tempos não se via; decisões difíceis foram exigidas o tempo todo, na tentativa de conciliar a vida, a saúde e os interesses econômicos.

Uma nova realidade se instalou e com ela um imenso desafio que implica na superação de uma lógica identitária, direcionada para a retomada de novas posturas de alteridade, diversidade e cooperação, conducentes à conciliação de diversos interesses e resultados. A fraternidade precisa ser (re) incorporada à vida cotidiana, posto que só assim "atitudes mais humanas poderão ser presenciadas. É a partir dessa condição que a sinfonia da convivência se torna uma melodia a ser entoada em todos os momentos da vida". (BASTIANI; PELLENZ; AQUINO, 2015, p. 985).

Nesse contexto, a família desponta como importante núcleo de cooperação e de solidariedade para a construção de uma sociedade mais fraterna. Mas para isso, é preciso que haja harmonia entre seus membros.

\section{0 princípio da fraternidade e da solidariedade no direito de família}

O Direito de Família no Brasil viveu seu grande momento de metamorfose com o advento da CFRB/88 e com a posterior edição do Código Civil de 2002. A família hierarquizada, patriarcal, desigual, patrimonial e que reconhecia apenas o casamento como forma de constituição, cedeu espaço para uma família mais democrática, que passou a valorizar cada um de seus membros, estabelecendo a igualdade entre eles, além de abrir espaço para novos arranjos familiares e reconhecer a socioafetividade como forma de parentesco.

Uma nova tábua axiológica passou a reger a construção do direito familista, fazendo ruir tradições seculares, ao mesmo tempo em que concebia uma família mais intimista e afetiva. Com objetivo de assegurar a comunhão plena de vida, estimulando o bem-estar de cada um de 
seus membros e fazendo com que a família sirva como espaço de proteção, o princípio celular da dignidade da pessoa humana permeou toda a sua estruturação.

Junto com a dignidade, outros princípios aparecem como pilares, a exemplo da liberdade, da igualdade e da solidariedade. E assim como no âmbito macro, a igualdade ocupou maior espaço, até mais do que o princípio da liberdade. A fraternidade, por sua vez, sequer é mencionada como princípio aplicável ao Direito de Família.

Tal qual ocorreu nas demais searas, também no direito familiar houve a substituição da fraternidade pelo princípio da solidariedade, que não tem merecido o devido destaque no Direito de Família.

A fim de tratar sobre essas questões e também de defender a fraternidade como importante princípio vetor da reconstrução e manutenção dos laços familiares, mormente pós pandemia da COVID-19, importa tecer, agora, maiores reflexões acerca da abrangência e compreensão dos princípios da igualdade, liberdade e da solidariedade especificamente no direito familiar.

O princípio da igualdade é o grande responsável pela democratização das relações conjugais e de filiação, estabelecendo uma revolução na estruturação das famílias. A igualdade colocou homens e mulheres em um mesmo patamar de condições, não só na condição de marido e esposa, mas também enquanto detentores do poder familiar, responsáveis pela criação e cuidados dos filhos. Com base na igualdade, proibiu-se discriminação e designações vexatórias para filhos oriundos de relações extraconjugais, além de colocá-los no mesmo nível de direitos e deveres dos filhos conjugais. A igualdade também foi responsável pela equiparação das entidades familiares, dando visibilidade para outros tipos de arranjos como a união estável e a família monoparental.

Já o princípio da liberdade preconizou a não interferência do Estado, da sociedade e dos entes familiares na constituição e extinção da família nuclear, ou seja, a escolha do projeto familiar, do seu formato, do regime de bens - com exceção das hipóteses contempladas no art. 1641 do CC - do planejamento em relação aos filhos e da definição dos credos e opiniões é de livre decisão do casal. Assim, também, a opção pelo término da relação. O exercício da liberdade substituiu o autoritarismo da família tradicional, permitindo a sua permanente constituição e constante reinvenção. (LÔBO, 2018).

A enorme relevância da igualdade e da liberdade na reestruturação ocorrida juridicamente no Direito de Família, responsável por conferir-lhe uma roupagem repersonalizada, não pode de modo algum deixar de lado sua vertente da solidariedade/fraternidade, necessária para o estabelecimento de vínculos responsáveis, cuidadosos e preocupados com a condição do outro. 
Na lei, o princípio da solidariedade aparece expressamente no art. 3, inc. I da CFRB/88, como um dos objetivos fundamentais da República Federativa do Brasil. Já no Direito de Família não consta de forma expressa, mas é facilmente extraído do dever imposto ao Estado, à sociedade e à família de zelar e proteger a unidade familiar (art. 226, CFRB), a criança, o adolescente (art. 227, CFRB) e o idoso (art. 230, CFRB). A Convenção Internacional sobre os Direitos da Criança e do Adolescente, incorporado pelo ordenamento brasileiro, reforça expressamente o direito serem educadas de acordo com os ideais proclamados na Carta das Nações Unidas, que contempla o espírito de solidariedade.

Em nível doutrinário, a solidariedade é trabalhada no sentido de dever de responsabilidade pelo outro, sendo a família apontada como o primeiro núcleo no qual deve imperar, posto que cabe aos entes da família o dever de auxiliar na promoção do livre desenvolvimento da personalidade de todos os membros, em atendimento aos deveres de respeito e tolerância, mas também no sentido de contribuir para autodeterminação do próximo. (ALMEIDA; RODRIGUES JÚNIOR, 2010).

A solidariedade chega a ser tratada, por Rolf Madaleno (2016, p. 89), como "princípio oxigênio" das relações familiares e afetivas, para quem "os vínculos só podem se sustentar e se desenvolver em ambiente recíproco de compreensão e cooperação, ajudando-se mutuamente sempre que se fizer necessário".

Do exposto, é possível concluir que a solidariedade tratada no Direito de Família é a chamada solidariedade horizontal, ou seja, aquele que preconiza a harmonização, a cooperação dos vínculos igualitários entre sujeitos, em total consonância com o princípio da fraternidade.

E apesar da fraternidade ser mais abrangente, serão aqui ambos os princípios tratados como sinônimos. Esse tratamento, inclusive, é o que fica evidente nas lições de Paulo Lôbo (2007) que, ao tratar sobre o princípio da solidariedade, aparenta fazer referência ao princípio da fraternidade, ao dizer que a solidariedade age como princípio fundamental do Direito de Família, ao lado da dignidade da pessoa humana. Em suas palavras:

A solidariedade e dignidade da pessoa humana são dois hemisférios indissociáveis do
núcleo essencial irredutível da organização social, política e cultural e do
ordenamento jurídico brasileiro. De um lado, o valor da pessoa humana enquanto tal,
e os deveres de todos para com sua realização existencial, nomeadamente o grupo
familiar; de outro lado, os deveres de cada pessoa humana com os demais, na
construção harmônica de sua dignidade. (LÔBO, 2007).

Este aspecto fica ainda mais claro quando trata sobre a necessária interação entre os sujeitos e a busca de equilíbrio, no mundo contemporâneo, entre o espaço público e o privado, asseverando ser a solidariedade esse elemento conformador dos direitos subjetivos. 
Essas são características mais próximas da fraternidade do que da solidariedade. Isso ocorre, como visto, pela natureza da solidariedade horizontal, que se confunde com a fraternidade. Mas para o autor, a explicação está no fato de que o constituinte optou por substituir a tradicional tríade francesa, pela liberdade, justiça e solidariedade, afirmando expressamente, que o apelo ético do passado que correspondia à fraternidade, converteu-se em dever jurídico de solidariedade. (LÔBO, 2007).

Outros autores, como Maluf (2018, p. 69) chegam a tratar a solidariedade como gênero do qual se extrai a fraternidade. Em suas palavras "a solidariedade origina-se nos vínculos de afetividade que marcam as relações familiares, abrangendo os conceitos de fraternidade e reciprocidade".

Conforme visto nas lições anteriores, a fraternidade é que engloba a solidariedade e não o oposto. Mas essa discussão se torna menos importante, quando se tem em vista que o principal objetivo é promoção do espírito e do exercício da fraternidade nas relações familiares em geral.

\section{A pandemia e as relações familiares: a fraternidade como novo horizonte}

Com a reestruturação do direito de família, alicerçada em novos valores e modelos, foi possível identificar a proteção da entidade, não mais por si mesma, ou em desconsideração à dignidade de cada um de seus membros, mas, e exatamente, pela consideração da individualidade de cada integrante, em compartilhamento com os demais.

O alicerce da família deixou de estar calcado na proteção patrimonial ou na estrutura patriarcal, para fincar raízes na valorização da convivência pelo compartilhamento de afetos e desejos, e, além disso, nos deveres e responsabilidades.

Conforme já ressaltado, a solidariedade/fraternidade deixou de ser considerada um valor ético, para ser tratada como princípio, razão pela qual passa se torna exigível, estando contemplada de forma tácita em vários artigos espalhados pelo Código Civil, a exemplo do art. 1.511, ao preconizar que o casamento estabelece comunhão plena de vida; ou dos arts. $1.566 \mathrm{e}$ 1.724 do $\mathrm{CC}$, ao estabelecerem os deveres recíprocos de respeito, assistência e consideração mútua entre os cônjuges e companheiros, ou, ainda, os deveres de criação e educação dos filhos (art. 1.634 do CC). O Estatuto da Criança e do Adolescente (Lei n. 8.069/90) reforça esses parâmetros de proteção e vida digna das crianças, assim como o Estatuto do Idoso (Lei n. $10.741 / 2003$ ) passa a prever o dever de amparo aos idosos. 
No campo jurisprudencial, para exemplificar, evidencia-se a solidariedade no reconhecimento da filiação socioafetiva, capaz de estabelecer vínculos de parentalidade entre pessoas não ligadas por laços sanguíneos, expressão máxima do afeto e da fraternidade.

Os avanços no plano jurídico, todavia, não foram suficientes para concretizar todos os objetivos do plano fático. Há um longo caminho a ser percorrido ainda, não só em termos legais como também e, principalmente, no mundo dos fatos.

Urge o despertar da consciência de que somos responsáveis não só pelo nosso bem-estar, como pela existência social e bem-estar do próximo. "É imprescindível o adimplemento dos deveres inderrogáveis de solidariedade, que implicam condicionamentos e comportamentos interindividuais realizados num contexto social."

Os mandamentos da fraternidade precisam ser estimulados. Como bem pontua Ildete Silva (2008, p. 419/420), se a fraternidade for realmente vivenciada nas relações humanas, pode ser capaz de gerar compromissos aptos a promoção de soluções para necessidades que resultam não só no próprio bem-estar, como no bem-estar do outro, “em um movimento circular, propício ao surgimento de uma mentalidade fraterna." (SILVA, 2008, p. 419-420).

A título exemplificativo, se a mentalidade sobre a adoção comportasse a exata dimensão da fraternidade e da solidariedade, provavelmente não mais se veriam as disparidades entre o número de interessados para a adoção e o número de crianças disponíveis para serem adotadas. Se a conta não fecha, considerando que há muito mais casais aptos à adoção e, ainda assim, milhares de crianças continuam aguardando a concretização do direito de ter uma família, é porque há algo que precisa ser mudado urgentemente.

A violência doméstica, que causa tantas feridas, que tira tantas vidas, poderia ser evitada se a igualdade e a fraternidade fossem, de fato, praticadas; o desprezo, o abandono moral e material dos filhos não ocorreria se a responsabilização pelos seus fosse exercida; a alienação parental não teria vez, caso os pais priorizassem o melhor interesse dos filhos; o desgaste dos avós seria superado, sem a necessidade de ação judicial para assegurar o convívio com os netos.

Caso todos compreendessem a importância da incorporação de atitudes fraternais nas suas relações com seus familiares, e também com o próximo, reconhecendo as fragilidades comuns, a autorresponsabilização e a cooperação, as relações poderiam ser mais autênticas e felizes.

E ainda assim, consciente de que a família é um núcleo propenso às desavenças e dessarranjos, o reconhecimento da importância do diálogo, do respeito e da tentativa de compor as suas demandas, sem a necessidade de recorrer ao litígio, já seriam um grande avanço rumo à concretização da fraternidade. 


\section{Considerações finais}

Diante de todas as infindáveis dificuldades ocorridas diariamente no convívio entre os casais e entre pais e filhos, agravadas no contexto da pandemia, exsurge ainda mais urgente a tentativa de disseminação do conteúdo e exercício da mentalidade e atitudes fraternais e solidárias.

A fraternidade e a solidariedade devem ser revisitadas, o que potencializará uma importante mudança comportamental e criará novos hábitos e habilidades. A fraternidade apresenta-se como a raiz mais profunda apta a gerar relações genuínas, de respeito recíproco e cooperação.

Se a família tradicional, baseada no autoritarismo, na desigualdade entre cônjuges e filhos, no casamento como única forma de constituição de família, cedeu espaço para uma família plural, democrática e que preconiza a igualdade, essa mesma família contemporânea precisa abrir efetivamente espaço para a realização concreta dos valores fraternais.

E isso somente será possível se cada um fizer a sua parte. Se cada um assumir a sua responsabilidade e passar a ter um olhar mais compreensivo e pacificador para que a proposta da fraternidade não seja concretizada apenas em nível retórico.

A resistência precisa ser quebrada, o abismo entre o sentido utópico ou ideal e o sentido prático da fraternidade precisa ser preenchida.

\section{REFERÊNCIAS}

AQUINI, Marco. Fraternidade e Direitos Humanos. In: Baggio, Antônio Maria (org.). O princípio esquecido, v. 1. A fraternidade na reflexão atual das ciências políticas. Vargem Grande Paulista, SP; Editora Cidade Nova, 2008.

ALMEIDA, Renata Barbosa; RODRIGUES JUNIOR, Walsir. Direito Civil: Famílias. Rio de Janeiro: Lumen Juris, 2010.

BAGGIO, Antonio Maria (Org). O princípio esquecido. São Paulo: Cidade Nova, 2009.

BASTIANI, Ana Cristina; PELLENZ, Mayara; AQUINO, Sergio Ricardo. Metamofoses do Direito: Exigências Constitucionais a partir da fraternidade e da solidariedade. In Novos Estudos Jurídicos, 2015.

GIMENEZ, Charlise. Alteridade e Fraternidade nas relações sociais: perspectivas para a mediaçao dos conflitos. Porto Alegre: Editora Fi, 2018. 
LÔBO, Princípio da Solidariedade Familiar. In Revista Brasileira de Direito de Família e Sucessões, 2007. Disponível em: <www.ibdfam.org.br/-img/congressos/anais/78.pdf $>$ Acesso em: $10 / 06 / 20$

MADALENO, Rolf. Direito de Família. São Paulo: Forense, 2017.

MATINELLI, Salvati. Os princípios da revolução francesa e a sociedade moderna. Milão: Il Saggiatore. 1998.

MORAIS, Silvia R.R. Lemos; TENÓRIO, Robinson Moreira. Considerações introdutórias sobre as diferenças entre os conceitos de fraternidade e solidariedade.

PATTO, Pedro Maria Godinho Vaz. In PIERRE, Luiz A.A; CERQUEIRA, Maria ; FURLAN, Vanessa; CURY, Munir. Fraternidade como Categoria Jurídica. São Paulo: Editora Cidade Nova, 2013.

PIZZOLATO, Filippo. A Fraternidade no ordenamento jurídico italiano. In: BAGGIO, Antônio Maria (Org.). O Princípio Esquecido, v.1. Tradução de Durval Cordas, Iolanda Gaspar, José Maria de Almeida. Vargem Grande Paulista, SP. Editora Cidade Nova, 2008.

PREIS, Marco Antônio; LYRA, José Francisco Dias da Costa. Deveres fundamentais e a dimensão da solidariedade no direito: condições de possibilidade para um direito fraterno. In

GIMENEZ. Charlise Paula Colet. Alteridade e Fraternidade nas Relações Sociais: perspectivas para a mediação de conflitos. Porto Alegre: Editora Fi, 2018.

SILVA, Ildete Regina Vale. Estudos Preliminares sobre a Fraternidade no Direito. In Revista Eletrônica Direito e Política. Univali, Itajaú, v. 3, n.3, 2008.

TOSI, Giuseppe. A fraternidade é uma categoria política. In BAGGIO, Antonio Maria (Org.). O princípio esquecido: Exigências, recursos e definições da fraternidade na política. São Paulo: Cidade Nova, 2009. Tradução de Durval Cordas e Luciano Reis. 